\title{
Movements of humpback whales between Kauai and Hawaii: implications for population structure and abundance estimation in the Hawaiian Islands
}

\author{
Salvatore Cerchio $^{1, *}$, Christine M. Gabriele ${ }^{2, * *}$, Thomas F. Norris ${ }^{1}$, Louis M. Herman ${ }^{2}$ \\ ${ }^{1}$ Moss Landing Marine Laboratories, PO Box 450, Moss Landing, California 95039, USA \\ ${ }^{2}$ Kewalo Basin Marine Mammal Laboratory, 1129 Ala Moana Blvd, Honolulu, Hawaii 96814, USA
}

\begin{abstract}
Identification photographs of individual humpback whales Megaptera novaeangliae were used to investigate movements of whales between Kauai and Hawaii (approximately $500 \mathrm{~km}$ apart; the Hawaiian Islands, USA) during the winter and spring months of 1989, 1990 and 1991. A total of 1072 individuals were identified, with 40 individuals being sighted off both islands. There were 15 documented transits between islands within seasons; 9 whales traveled northwest (from Hawaii to Kauai), whereas 6 whales traveled southeast (Kauai to Hawaii). Simulation data indicated that these transitdirection proportions did not deviate from random expectations $(p=0.76)$; therefore, there was no directional trend to movement between the islands. The shortest observed transit was $8 \mathrm{~d}$, indicating that whales can move throughout the island chain in short periods. Males were significantly overrepresented in inter-island recaptures $(p \ll 0.001)$, and we suggest that males actively engaged in courtship behaviors are more wide-ranging. Whales did not show a significant trend to be captured off the same island in different years $(p=0.08$ for Kauai, $p=0.12$ for Hawaii); however, recaptures were few, power was relatively low, and 1 test approached significance. The observed number of within-season, between-island recaptures was significantly less than expected as determined by random simulations ( $p=0.013$ for Kauai, $p=0.008$ for Hawaii), indicating that, during a season, whales are more likely to be recaptured off the island of initial capture. There was also evidence suggesting that sub-groups of whales moved among the islands in loose aggregations: within seasons, the number of pairs of individuals captured off both islands within 7 d of each other was significantly greater than expected in random simulations $(p=0.038)$. We conclude that complete random mixing of whales among the islands is unlikely, and should not be assumed in the context of mark-recapture abundance estimation. Larger samples with greater coverage of the Hawaiian Islands and higher recapture probability will be needed to elucidate movement patterns of the population.
\end{abstract}

KEY WORDS: Humpback whale - Mark-recapture - Photographic identification Migratory movements

\section{INTRODUCTION}

Humpback whales Megaptera novaeangliae migrate annually between summer feeding areas in high latitude waters and winter breeding areas in

\section{Present addresses:}

- Department of Biology and Museum of Zoology, University of Michigan, 1109 Geddes Ave., Ann Arbor, Michigan 48109-1079, USA.E-mail:sal@umich.edu

-Glacier Bay National Park, PO Box 140, Gustavus, Alaska 99826, USA low latitude waters. Photographic identification of individual humpback whales using fluke pigmentation patterns (Katona et al. 1979) has been applied to mark-recapture techniques to track individuals, determine migratory patterns, and assess population characteristics and abundance (Baker \& Herman 1981, 1987, Darling \& McSweeney 1985, Baker et al. 1986, Darling \& Morowitz 1986, Calambokidis et al. 1990). Whale movement within the Hawaiian wintering grounds, the subject of the present study, has bearing on estimation of population structure and abundance. 
Researchers have estimated the abundance of humpback whales off the Hawaiian Islands by employing a variety of mark-recapture analyses and data on individually identified whales (Darling et al. 1983, Baker et al. 1986, Darling \& Morowitz 1986, Baker \& Herman 1987. Cerchio 1995, 1998, in this issue). Markrecapture estimates of abundance off the Hawaiian Islands range from 1407 (Baker \& Herman 1987) and 2100 (Darling \& Morowitz 1986) in the late 1970s/early 1980 s to over 4000 (Cerchio 1995, 1998) a decade later. Each of these studies attempted to estimate abundance from a portion of the total range of the population, thus implicitly assuming random mixing throughout the range. However, Darling \& Morowitz (1986) and Cerchio $(1995,1998)$ reported evidence of varying composition of individuals from year to year, indicating a potential bias in abundance estimates from singleisland data sets.

While wintering off the Hawaiian Islands, whales appear to move throughout the island chain rather than remaining resident of any single island (Baker \& Herman 1981, Darling \& McSweeney 1985, Baker et al. 1986, Darling \& Morowitz 1986, Cerchio et al. 1991). The pattern or extent of this movement is not well understood. After 3 yr of aerial surveys over the main Hawaiian Islands, Baker \& Herman (1981) found that peak abundance off each island was staggered temporally through the season from Hawail to Oahu, whereas abundance off Kauai was independent of the trend. They concluded that whales move through the islands in a general northwesterly direction starting from the island of Hawaii, and that Kauai may represent a partially segregated subgroup. Baker \& Herman (1981) reported that 6 individual whales moved from

\section{Hawaiian Islands}
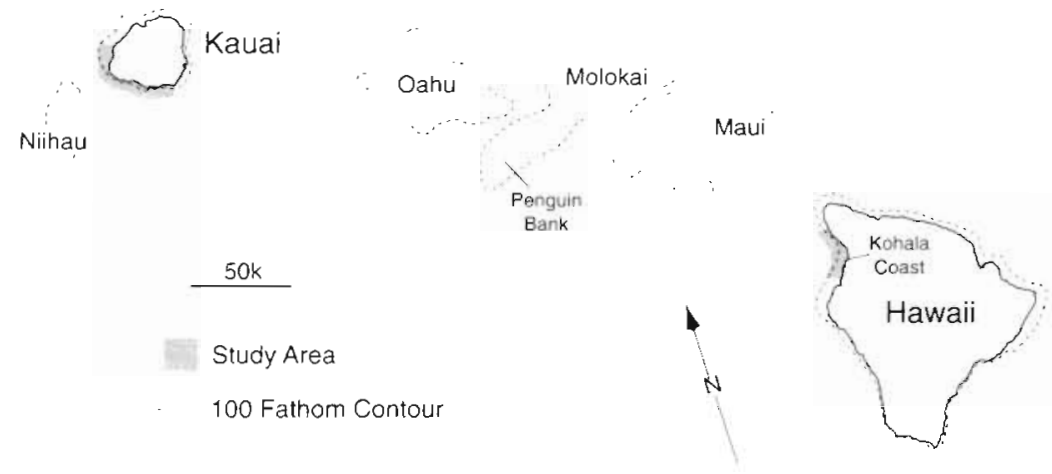

Fig. 1. Hawaiian Islands, USA. Shaded areas off Kauai and Hawaii represent general region of coast covered in this study, but do not necessarily indicate offshore extent of range sampled. Off Kauai, the study region was the south and west coasts. Off Hawaii, the study region was the Kohala coast along the north west side of the island
Hawail to the Maui region and 1 from Maui to Oahu, supporting a general northwest movement trend. However, Darling \& Morowitz (1986) reported 5 cases of whales moving from Maui to Hawaii, and presented evidence indicating that the majority of the population was present off Maui through peak season. Darling \& McSweeney (1985) found that $33 \%$ of whales identified off Kona, Hawaii ( $n=200$ ), between 1978 and 1981 were also identified off West Maui (no information on direction of movement was given), and postulated that whales regularly traveled between Maui and Hawaii.

The distribution and mixing of a population throughout its range is an important consideration when estimating abundance using mark-recapture methods (Seber 1982, Hammond 1986, 1990). Previous estimates of humpback whale abundance for the Hawaiian Islands were made with samples collected in only a small portion of the species' winter range (e.g. off Maui or Hawaii) without considering the possible effects of non-random mixing or distribution among the islands. If mixing among the islands is not random, the type and degree of bias will depend upon the distribution patterns of individuals in the population and the relationship of the sampling region to the range of the population. Hammond (1986) discusses in detail problems associated with the assumption of 'equal probability of sighting' when sampling a highly mobile population in a small portion of its range.

The goal of this study was to investigate the movement of individually identified humpback whales between Kauai and Hawaii, the 2 most distantly separated islands in the main Hawaiian Island chain. We attempted to determine whether whales randomly distributed themselves between the islands within and among sample years, and examined the pattern of recaptures in terms of sex composition, direction of movement and temporal trends.

\section{METHODS}

Identification photographs of individual humpback whales were collected during 2 independent research projects off the Hawaiian islands of Kauai and Hawaii (Fig. 1). The 2 study areas were approximately $500 \mathrm{~km}$ apart on opposite ends of the main Hawailan Island chain. Sampling was conducted from early/mid-January to mid/late-April during 1989, 1990 and 1991. Effort typically commenced off Hawaii earlier than Kauai by 1 to 2 wk each season; sampling ended off Kauai 3 wk later in 
1989, and only several days later in 1990 and 1991. Off Kauai, sampling was conducted off the south and west coasts from 1 or 2 boats (see Cerchio 1998). Off Hawaii, the study area encompassed the Kohala coast on the northwest side of the island. Two boats were used during all years with one boat concentrating effort toward photographic identification, and the other boat doing photographic work about $50 \%$ of the time.

Photographs were taken with 400 ASA black and white film using $35 \mathrm{~mm}$ SLR cameras with 200 to $300 \mathrm{~mm}$ lenses. Composition of pods and behavioral categories of photographed individuals were noted, and sex was inferred from behavior when possible. Individuals with closely associated calves were assumed to be mothers and, therefore, female (Glockner 1983, Glockner-Ferrari \& Ferrari 1985, Gabriele 1992\}; single individuals escorting mothers and calves were assumed to be male (Glockner 1983, GlocknerFerrari \& Ferrari 1985, Gabriele 1992); and individuals that were confirmed to be singing were assumed to be male (Darling 1983, Darling et al. 1983, Glockner 1983, Glockner-Ferrari \& Ferrari 1985)

Photographs from Kauai and Hawaii were first analyzed separately, to determine numbers of different individuals photographed and repeat sightings within and among years at each site. Photographs from both areas were then compared to each other on a year by year basis to determine the number of individuals photographed in both areas during the same and different years. All photographs were compared for investigation of individual movements, regardless of quality; however, photographs judged to be of insufficient quality (by S.C. or C.M.G.) for a positive identification (independent of fluke distinctiveness) were not used in tests of recapture probability. Aspects of photographs considered were focus, grain size of image, lighting, horizontal and vertical angle of flukes, and percentage of flukes visible. Each usable photograph of an individual's flukes was considered a 'capture,' and subsequent photographs of that individual were considered 'recaptures.' Each year was considered a single sampling event.

To determine whether mixing of animals between the 2 islands was random, we addressed 2 questions: (1) Was the recapture probability on each island independent of initial area of capture across different years? and (2) Was the recapture probability within a single year independent of initial area of capture? To test whether recapture probability among years was independent of original location of capture, we adapted a method used to determine whether different subgroups within a population have equal probability of capture (Begon 1979, p. 62). If different recognizable subgroups have the same probability of capture, then the proportion of individuals from each subgroup recaptured in a second sample $\left(n_{2}\right)$ would be equivalent to the proportion of each subgroup in the first sample $\left(n_{1}\right)$. In the present analysis, 2 subgroups were considered: whales initially captured off (1) Kauai and (2) Hawaii in a sample year $\left(n_{1}\right)$. If captured individuals assorted themselves randomly among the islands in subsequent years, then recaptures $\left(m_{21}, m_{31}\right.$, etc. $)$ off each island would be comprised of whales captured off Kauai and Hawaii in the same proportion as in the initial sample $\left(n_{1}\right)$. It was assumed that whales marked off each island had equivalent survival rates. A $2 \times 2$ contingency table (continuity corrected) was used to test whether the probability of a whale being recaptured was independent of original capture area. Recaptures off each island were considered separately for each year of initial capture (1989 and 1990), resulting in 2 independent tests for each island. Tests for heterogeneity of $2 \times 2$ contingency tables (Zar 1984, p. 67) were then performed to determine whether data from different years could be pooled, resulting in 1 test per island.

To test whether recapture probability within years was independent of original capture location, we used a Monte Carlo randomization test (Manly 1997). Within-year recaptures were based upon simultaneous samples on the 2 islands, so more conventional recapture statistics (such as the subgroup method above) would not be appropriate; dividing each season into halves and treating them as 2 samples would have made mark-recapture tests possible, but resulted in too few recaptures for meaningful results. Therefore, we constructed a simple model to simulate random recaptures, and evaluated the probability of getting the observed number of between-island recaptures in the random-recapture data set. If the observed number of between-island recaptures deviated significantly from that generated by the random model, then we would conclude that recapture was not independent of island of initial capture. The model was constrained to the actual capture events in the real data (e.g. on 13 February 1989: 3 captures off Kauai, 5 off Hawaii, etc.) and the number of within-season recaptures from each island for each year. For example, in 1989 a total of 16 individuals were recaptured from Hawaii (regardless of recapture location); the model assigned 16 individuals a random capture date on Hawaii and a random recapture date and island from all possible capture events in the real 1989 data. Use of the actual data controled for bias that may have been introduced due to temporal differences in sampling between islands. Minimum inter-island recapture period was constrained to $8 \mathrm{~d}$ (the shortest observed inter-island transit). The probability of obtaining the observed capture pattern was then assessed by the number of trials out of 1000 simulations that yielded less than or equal to 
the observed number of between-island captures; a probability of less than 0.05 was chosen as a significant departure from random mixing between islands, indicating a higher likelihood of recapture on the same island.

\section{RESULTS}

\section{Individual movement}

A total of 1072 individual. humpback whales were identified from the 753 individuals captured off Hawaii and the 359 captured off Kauai during the study (Table 1). The smaller sample sizes from Kauai in 1989 and 1990 reflected the lower degree of effort. A total of 40 different individuals were photographed off both islands, with 15 within-year recaptures (transits between islands) and 31 between-year recaptures (of 29 different individuals) between islands (Table 2). Of the 15 within-year recaptures, 8 were behaviorally sexed as male and none as female. Of the 29 individuals recaptured across years, 12 were sexed as males and 1 as female (without a calf on both occasions but known to be a female from previous sightings with a calf). The sex ratio of recaptured individuals differed significantly from that of the entire sample, 72 known females and 157 known males $\left(\chi_{1}^{2}=6.197, p=0.01\right.$ when considering only known males and females; $\chi_{2}^{2}=$ $39.320, \mathrm{p} \ll 0.001$ when considering whales of unknown sex as well) and subdivision of the table indicated significance was due to overrepresentation of known males in the recaptured individuals.

Table 1. Megaptera novaeangliae. Numbers of individual whales photographed. Values in parentheses indicate number of repeat sightings of individuals photographed more than once that year Totals are corrected for recaptures among years and between islands

\begin{tabular}{|lcccc|}
\hline & 1989 & 1990 & 1991 & All years \\
\hline Hawaii & $231(61)$ & $286(54)$ & $268(32)$ & 753 \\
Kauai & $80(4)$ & $91(5)$ & $198(31)$ & 359 \\
Total & $307(66)$ & $373(62)$ & $459(68)$ & 1072 \\
\hline
\end{tabular}

Table 2. Megaptera novaeangliae. Summary of individuals photographed off both Kauai and Hawaii within the same year and between different years

\begin{tabular}{|lcccc|} 
& Males & Females & Unknown & Total \\
\hline Within years & 8 & 0 & 7 & 15 \\
Between years & 14 & 1 & 16 & 31 \\
Different individuals & & & & 40
\end{tabular}

Of the 15 within-year transits, 9 whales moved northwest from Hawaii to Kauai, whereas 6 moved southeast from Kauai to Hawaii (Tables $3 \& 4$ ). Photographs of 2 of these whales were of poor quality (Table 4, identification [ID] no. 273 and 384). Although the distinctiveness of their flukes allowed confirmed matches, they were excluded from statistical analysis to avoid biasing the sample toward distinctive animals. The shortest inter-island sighting interval was $8 \mathrm{~d}$, for ID no. 314, a whale of unknown sex first sighted off Hawaii on 18 March 1991 and then off Kauai in a competitive group on 26 March 1991. The actual transit time is likely to have been shorter than $8 \mathrm{~d}$ since the precise day of departure and arrival were unknown. The shortest apparent southeast transit was of ID no. 107. a whale of unknown sex sighted off Kauai on 22 February 1990 and then 17 d later off Hawaii in a competitive group on 11 March 1990. This distinctive individual was missing its right tail fluke and had many

Table 3. Megaptera novaeangliae. Direction of travel of within-year recaptures between Kauai and Hawaii

\begin{tabular}{|lcccc|}
\hline & 1989 & 1990 & 1991 & All years \\
\hline Hawaii to Kauai & 3 & 2 & 4 & 9 \\
Kauai to Hawaii & 1 & 2 & 3 & 6 \\
\hline
\end{tabular}

Table 4. Megaptera novaeangliae. Within-year recaptures between Kauai and Hawaii, indicating catalogue number of individual (ID no. from Kauai catalogue), island (KI = Kauai, $\mathrm{HI}=$ Hawaii) and date of each sighting, sighting interval in days, and sex if known ( $M=$ male, $U=$ unknown). Bold type indicates sightings of individuals made within $7 \mathrm{~d}$ of each other; 1000 simulations of a random recapture model indicated $\mathrm{p}=0.038$ of getting 1 pair of individuals in each year that were sighted within. $7 \mathrm{~d}$ of each other on both islands (see text for details of model)

\begin{tabular}{|cllcc|}
\hline ID no. & \multicolumn{1}{c}{$\begin{array}{c}\text { First } \\
\text { sighting }\end{array}$} & $\begin{array}{c}\text { Second } \\
\text { sighting }\end{array}$ & $\begin{array}{c}\text { Interval } \\
\text { (d) }\end{array}$ & Sex \\
\hline 019 & HI 30 Jan 1989 & KI 11 Apr 1989 & 7 7 & M \\
$\mathbf{0 6 3}$ & HI 20 Feb 1989 & KI 26 Apr 1989 & $\mathbf{6 5}$ & M \\
$\mathbf{2 7 3}$ & HI 27 Feb 1989 & KI 30 Apr 1989 & $\mathbf{6 2}$ & M \\
051 & KI 4 Feb 1989 & HI 21 Mar 1989 & 45 & M \\
139 & HI 24 Jan 1990 & KI 1 Feb 1990 & 28 & $\mathrm{U}$ \\
1.79 & HI 14 Feb 1990 & KI 7 Apr 1990 & 52 & M \\
$\mathbf{1 0 7}$ & KI 22 Feb 1990 & HI 11 Mar 1990 & $\mathbf{1 7}$ & $\mathrm{U}$ \\
$\mathbf{1 5 9}$ & KI 15 Feb 1990 & HI 14 Mar 1990 & $\mathbf{2 7}$ & $\mathrm{U}$ \\
$\mathbf{2 1 4}$ & HI 4 Feb 1991 & KI 22 Feb 1991 & 18 & $\mathrm{U}$ \\
$\mathbf{2 5 8}$ & HI 4 Feb 1991 & KI 24 Mar 1991 & 48 & $\mathrm{M}$ \\
$\mathbf{3 1 4}$ & HI 18 Mar 1991 & KI 26 Mar 1991 & 8 & $\mathrm{U}$ \\
$\mathbf{1 2 7}$ & HI 18 Mar 1991 & KI 16 Apr 1991 & 29 & M \\
$\mathbf{3 8 4}$ & KI 9 Feb 1991 & HI 20 Mar 1991 & 39 & $\mathrm{U}$ \\
$\mathbf{2 1 9}$ & KI 27 Feb 1991 & HI 20 Mar 1991 & $\mathbf{2 1}$ & $\mathrm{U}$ \\
$\mathbf{2 9 6}$ & KI 27 Feb 1991 & HI 25 Mar 1991 & $\mathbf{2 6}$ & $\mathbf{M}$ \\
& & & & \\
\hline
\end{tabular}


scars indicating an orca attack. That both of these individuals were sighted in competitive groups suggests they were likely males (Clapham et al. 1992). The mean sighting interval for all between-island recaptures was $33.5 \mathrm{~d}(\mathrm{SD}=17.5 \mathrm{~d}$, range $=8$ to $71 \mathrm{~d})$. The mean sighting interval for northwest transits was $37.4 \mathrm{~d}$ ( $\mathrm{SD}=22.4$, range $=8$ to $71 \mathrm{~d})$, whereas for southeast transits it was 27.2 days $(\mathrm{SD}=10.7$, range $=17$ to $45 \mathrm{~d})$.

There was some indication of synchronous, or at least concurrent, inter-island movement among recaptured individuals (Table 4). In 1989, 2 individuals (ID no. 063 and 273, both males) were photographed within $7 \mathrm{~d}$ of each other off Hawaii and then photographed later in the season within $4 \mathrm{~d}$ of each other off Kauai. In 1990, 2 individuals (ID no. 107 and 159, both of unknown sex) were photographed within $7 \mathrm{~d}$ of each other off Kauaj and then within $3 \mathrm{~d}$ of each other off Hawaii. In 1991, 2 individuals (ID no. 219, unknown sex, and 296, male) were photographed off Kauai on 27 February and then within $5 \mathrm{~d}$ of each other off Hawaii. ID no. 384 (unknown sex), photographed off Kauai $18 \mathrm{~d}$ prior to ID no. 219 and 296, was photographed off Hawaii on the same day as ID no. 219. Three additional individuals (not shown in Table 4) photographed off Kauai on 27 February 1991 (in the same pods as ID no. 219 and 296) were photographed off Hawaii the previous year between 14 March and 23 March 1990. Two pairs of individuals (ID no. 214, unknown sex, and 258, male, and ID no. 314, unknown sex, and 127 , male) were also photographed on the same days off Hawaii, and then later in the season off Kauai, however in different months.

To assess the probability of observing these movement patterns by chance, a model was constructed similar to that described for within-season recapture analysis. For each year, the model randomized the capture and recapture date on each island for the number of observed transits between islands (4 in 1989, 4 in 1990 and 7 in 1991). The model was constrained to accept only trials in which the transit time was greater than or equal to $8 \mathrm{~d}$; island of initial capture was not constrained, but island of recapture was constrained to 'not island of initial capture'. This allowed us to evaluate the proportion of northwest transits to southeast transits, as well as the probability of the synchronous movement observed in the actual data. The probability in 1000 trials of at least 6 southeast transits was 0.76 (mean southeast transits $=5.2$, mean northwest transits $=9.8$ ), and 0.17 for exactly 6 southeast transits, indicating that the observed direction of movement did not deviate from that expected at random given the sampling dates on each island. As a test of the observed pattern of synchronous movements, the probability of getting at least 1 pair of individuals in each year cap- tured within $7 \mathrm{~d}$ of each other on both islands was 0.038 . This is a conservative test since it does not consider that several additional transiting individuals were captured within a short time-frame on only 1 island, nor that 3 individuals were captured off Hawaii within 9 d in 1990 and then off Kauai on the same day in 1991. This probability indicates that the observed pattern of synchronous movements deviates significantly from that expected at random.

\section{Across-year mixing}

Contingency table analysis did not allow us to reject the null hypothesis that recapture probabilities in subsequent years off each island were independent of area of initial capture (Table 5). For each island, samples from different years were homogeneous (for Kauai, heterogeneity $\chi_{1}^{2}=1.926, p=0.165$; for Hawaii, heterogeneity $\chi_{1}^{2}=0.3585, p=0.549$ ), allowing pooling of data. Off Kauai, the observed number of recaptures from Kauai was greater than the expected value; however, the relationship was not statistically significant $(p=0.08$; Table 5$)$. Since this test approached significance, an additional investigation of these data were made. When recaptures off Kauai were subdivided by year, animals initially captured in 1989 were more likely to be recaptured again off Kauai, and contributed substantially to the chi squared value $\left(\chi_{1}^{2}=\right.$ $4.1848, p=0.041)$, whereas animals initially captured in 1990 were recaptured in expected proportions off each island and contributed very little $\left(\chi_{1}^{2}=0.0090, p=\right.$ 0.924). Each of these single capture-year tables contained 1 expected value below 5.0, increasing the likelihood of an inflated chi squared value and false rejec-

Table 5. Megaptera novaeangliae. Across-year probability of capture tests. $2 \times 2$ contingency tables (corrected for continuity) were used to test whether recapture probability across years was independent of initial area of capture (see text for details). When recaptures off Kauai are subdivided by year, whales initially captured in 1989 were significantly more likely to be captured again off Kauai $\left(\chi_{1}^{2}=4.1848, p=0.041\right)$; however, this was not so for animals initially captured in 1990

$\left(\chi_{1}^{2}=0.0090, p=0.924\right)$. Obs.: observed; Exp.. expected

\begin{tabular}{|c|c|c|c|c|c|c|}
\hline \multirow[t]{3}{*}{ Recaptured } & \multicolumn{4}{|c|}{ Initially captured } & \multirow[t]{3}{*}{$x_{1}^{2}$} & \multirow[t]{3}{*}{$\mathrm{p}$} \\
\hline & \multicolumn{2}{|c|}{ Off Kauai } & \multicolumn{2}{|c|}{ Off Hawaii } & & \\
\hline & Obs. & Exp. & Obs. & Exp. & & \\
\hline \multicolumn{7}{|l|}{ Off Kauai } \\
\hline Recaptured & 11 & 6.7 & 16 & 20.3 & & \\
\hline Not recaptured & 159 & 163.3 & 501 & 496.7 & 3.019 & 0.082 \\
\hline \multicolumn{7}{|l|}{ Off Hawaii } \\
\hline Recaptured & 18 & 12.9 & 34 & 39.1 & & \\
\hline Not recaptured & 152 & 157.1 & 483 & 477.9 & 2.397 & 0.121 \\
\hline
\end{tabular}


tion of the null hypothesis (Zar 1984). Off Hawaii, there were more recaptures from Kauai than expected, however the difference was not significant (Table $5 ; \chi_{1}^{2}=$ 2.3976, $\mathrm{p}=0.12$ )

\section{Within-year mixing}

To evaluate within-year mixing, a fair test would have to consider only a portion of within-island recaptures to compensate for transit time of between-island recaptures. It is clear that we cannot count withinisland recaptures shorter than the minimum transit time between islands. Considering only within-year recaptures of greater than or equal to $8 \mathrm{~d}$ (the shortest transit), the mean interval of within-island recaptures, $20.3 \mathrm{~d}(\mathrm{n}=86)$, is shorter than the mean of transits, $33.5 \mathrm{~d}$. This suggests that within short time frames individuals are more likely to be recaptured off the same island, which is likely due to the distance involved in the transit and the low likelihood of mixing within the short period. Therefore, we considered only those within-island recaptures with a recapture interval greater than $\bar{x}-1 \mathrm{SD}$ of the observed transits $(33.5-17.5=15 \mathrm{~d})$. This resulted in 49 within-island recaptures (12 off Kauai and 37 off Hawaii) and a mean recapture interval of $27.0 \mathrm{~d}$, which is closer to the mean transit time between islands. Therefore, in our model we randomly assigned recapture dates and islands to 17 whales recaptured from Kauai (12 within Kauai and 5 Kauai-Hawaii recaptures) and 45 whales recaptured from Hawaii (37 within Hawaii and 8 Hawaii-Kauai recaptures). We then ran 1000 simulations to determine the probability of getting the observed number of

Table 6. Megaptera novaeangliae. Within-year recapture simulation results. A model was constructed that assigned a random recapture date and island to the number of individuals recaptured from each island among all possible capture events in the real data set (see text for details of model). The mean number of recaptures within and between islands is shown for 1000 trials of simulated data (Rand.), along with the probability of getting less than or equal to the observed (Obs.) number of between-island recaptures in the random-recapture data set (e.g. of the 17 individuals recaptured from Kauai, there was $p=0.013$ of getting 5 or fewer of them recaptured off Hawaii at random)

\begin{tabular}{|lcccc|}
\hline \multirow{2}{*}{ Recaptured } & \multicolumn{4}{c|}{ Initially captured } \\
& \multicolumn{2}{c|}{ Off Kauai } & \multicolumn{2}{c|}{ Off Hawaii } \\
& Obs. & Rand. & Obs. & Rand. \\
\hline Off Kauai & 12 & 7.1 & 8 & 15.7 \\
Off Hawaii & 5 & 9.9 & 37 & 29.3 \\
p of observed & 0.013 & & 0.008 & \\
in random data & & & & \\
\hline
\end{tabular}

between-island recaptures for individuals initially captured off each island (Table 6). For Kauai data, the probability of getting 5 or fewer Kauai to Hawaii recaptures was 0.013 ; for Hawaii data, the probability of getting 8 or fewer Hawaii to Kauai recaptures was 0.008 . Therefore, we observed a significantly higher number of within-island recaptures than expected at random.

\section{DISCUSSION}

This study presents the first documentation of individual humpback whales moving across the entire main Hawaiian Island chain. Within seasons, whales moved in both directions, some in a relatively short period of time. Those of known sex were primarily male. There was also evidence of synchronous or concurrent movement among transiling individuals. Although our results support the possibility of equal interchange between Kauai and Hawaii among years, they indicate a low probability of mixing during a given winter season. We will discuss the implications of our findings, first regarding movements of individuals and then regarding mixing of the population and implications for abundance estimation.

\section{Individual movements}

The shortest observed inter-island transit (8 d) demonstrates that whales can travel throughout the island chain in short periods of time. The average travel speed for this animal would have been $2.6 \mathrm{~km}$ $\mathrm{h}^{-1}$ (1.4 knots), if it traveled non-stop on a direct course. Bauer (1986) observed an average swimming speed of $4.44 \mathrm{~km} \mathrm{~h}^{-1}$ and a maximum of $11.4 \mathrm{~km} \mathrm{~h}^{-1}$ over short distances during shore-based observations of humpback whales off Maui. Given its lower average rate of travel, and knowledge of humpback whale social behavior (Darling 1983, Mobley \& Herman 1985), it seems likely that the individual we report traveled with variable speed, diverged from a straight-line course between Kauai and Hawaii, and perhaps lingered in other areas of the Hawaiian Islands during its transit. Combined with relatively low within-season, within-island recapture frequencies (Table 1; Gabriele 1992), this short inter-island transit time suggests that wintering humpback whales tend to be mobile, not commonly remaining in 1 area for extended time periods. Even whales recaptured of the same island after as little as a week may have traveled considerable distances in the intervening period, a factor that must be considered when mark-recapture data are used to evaluate residency trends off specific islands. 
Although the sample of documented within-year transits is relatively small ( $\mathrm{n}=15)$, there appears to be equal probability of whales moving to or from Kauai and Hawaii (Table 3). Transits also occurred throughout the season, with no documented tendency for movement in either direction earlier or later in the season (Table 4). Baker \& Herman (1981) suggested that the predominant movement through the chain is northwesterly; however, their conclusion was based on temporal trends in peak abundance rather than movements of identified individuals. Temporal staggering of peak abundance does not necessarily require that all animals move in a conveyor-belt fashion. There is likely bi-directional movement between islands throughout the season, as suggested by this study, Darling \& Morowitz (1986) and Darling \& McSweeney (1985), whereas the period of peak concentration may vary sequentially throughout the islands as reported by Baker \& Herman (1981)

Only 1 known female was sighted at more than 1 island within or between years (Table 2), and hence, the sex ratio of inter-island recaptures was heavily skewed towards males. This may have reflected a bias in our sample due at least partly to males being more readily identifiable behaviorally. Gabriele (1992) reported that $25 \%$ of males and $17 \%$ of females were sighted on more than $1 \mathrm{~d}$ off Hawaii and Maui, and that male sighting intervals were longer; both of these observations would also result in higher recapture probabilities for males as opposed to females. Regardless of a male bias in our sample, however, males were significantly overrepresented in the inter-island recaptures. Male humpback whale mating strategies may entail wide-ranging travel to increase the number of potential mates encountered, particularly if females are indeed less mobile within the wintering area. We surmise that the whales most likely to be sighted at both Kauai and Hawaii were those actively engaged in male courtship behaviors (i.e. escorting or singing). This is supported by the observation that unknown-sex whales were significantly underrepresented in interisland recaptures las shown by the much larger $\chi^{2}$ value calculated when unknowns were included in the contingency table, and by subdivision of the $\chi^{2}$ ).

The timing of some recaptures between Kauai and Hawaii indicated that some individuals may move as a loose aggregation. The sample is small 15 of 1072 ind.); however, a statistically significant deviation from a random recapture pattern, as indicated by our simulations, suggests that at least some individuals may have moved through the islands in a coordinated fashion. It is striking that 3 pairs were sighted on both islands within several days of each other, and an additional 5 individuals were sighted on 1 island on the same day (Table 4). This amounts to 11 of 15 transiting whales showing some degree of synchronized timing with another individual. Darling (1983) reported similar timing of capture among groups of individuals photographed in Hawaii and Alaska; 4 groups (from 2 to 5 individuals) were photographed off west Maui, and on either the Frederick Sound or Prince William Sound, Alaska, summer grounds, within $10 \mathrm{~d}$ to $3 \mathrm{wk}$ of each other, with each group sighting separated by up to $3.5 \mathrm{yr}$. If subgroups within a population tended to migrate or move within the wintering grounds in loose aggregations, as suggested by our study and Darling (1983), this would have important consequences for abundance estimation, including non-random emigration and non-independence of individual capture probabilities.

\section{Population mixing and implications for abundance estimation}

Considering the size of the combined Kauai and Hawaii samples (1072 individuals) and the relatively small number of individuals in both samples (40), it superficially appears there may be some degree of segregation between whales wintering off the 2 islands, as suggested by Baker \& Herman (1981). However, the incidence of between-year recapture was low for whales returning to the same island as well as to different islands, and our analysis did not indicate evidence of across-year site fidelity. The sample size of recaptures was small and the estimated statistical power of the $\chi^{2}$ tests was relatively low lestimated power of 0.50 for recaptures off Kauai and 0.41 for recaptures off Hawaii Zar 1984, p. 397). This suggests that the size of our between-year samples may have been insufficient to detect a difference in recapture probability, if one existed. Furthermore, the test for recaptures off Kauai approached significance. A larger sample, including animals captured from other regions across the islands, may yet indicate some degree of site fidelity. Regardless, our analysis suggests that if a tendency for whales to return to the same islands exists, it is relatively small, supporting treatment of the Hawaiian Islands as a single population for purposes of abundance estimation. This is in contrast to the breeding regions off Mexico, where there appears to be some stratification between the Revillagigedos Archipelago and the Mexican mainland (Urbán et al. 1994), and off the Pacific islands of Japan, where there appears to be stratification between the Bonin and Ryukyu Islands (Darling \& Mori 1993).

Within years, our simulations indicated that whales had a significantly higher probability of recapture off the island from which they were originally captured than would be expected by random. This suggests 
there may be some degree of segregation between Kauai and Hawaii within a season. It is important to note that we are sampling either end of an extended range across the Hawaiian Islands. It is highly likely that there is greater within-season exchange between Hawaii and Maui (as reported by Darling \& McSweeny 1985) or between Kauai and Oahu or Maui. A more continuous sampling along the chain may reveal a gradient of exchange probability, decreasing with increasing distance, rather than segregation in a strict sense. Therefore, our results more precisely indicate that a whale has a greater likelihood of remaining in a local sub-region than of traveling to the far end of the island chain, and possibly that whales are more likely to visit either Hawaii or Kauai during a given year, rather than both.

We can propose 3 alternative hypotheses regarding distribution and mixing of humpback whales among the Hawaiian Islands, and predict the bias on abundance estimation associated with each when sampling off a single island. (1) If mixing across years is uniform and random throughout the islands, then estimates from single islands should not be biased, even if some individuals were absent or had very low capture probabilities in some years. (2) If there is consistent segregation of animals among the Hawaiian Islands, as suggested by Baker \& Herman (1981), then sampling off a single island would not be representative of the entire wintering population, heterogeneity would be introduced, and the abundance estimate would be biased negatively. (3) If subgroups within the population follow non-random movement patterns (i.e. movement that is not independent among individuals), exhibiting varying capture probabilities across years and among islands, single-island estimates could be biased positively due to temporary emigration. Using the analyses just described, and appropriate caution given the limitations of our relatively small sample of recaptures, we can begin to assess these 3 alternative hypotheses regarding population mixing.

If the results of our inter-island recapture analyses are accurate, then whales may mix randomly between Hawaii and Kauai between years, but during a season there may be some degree of segregation. In this scenario, some individuals would be more likely captured off 1 island in a given year. If the character of movement is random among individuals, this pattern would yield no associated bias in single-island estimates. Marked and unmarked animals throughout the islands would have the same probability of visiting the sampling area in any given year. Therefore hypothesis (1), that of random mixing and no bias, would apply. However, 2 lines of evidence argue against complete random mixing.

First, we cannot completely eliminate the possibility of non-random mixing between years due to the small sample of recaptures and near statistical significance of one test $(p=0.08$ for recaptures off Kauai, both years combined, and $\mathrm{p}=0.04$ for recaptures off Kauai from 1989 alone; Table 5). In a larger sample, we may yet find that whales return to specific islands with higher frequency. This would introduce heterogeneity of capture probabilities and negatively bias single-island abundance estimates, as described in hypothesis (2). This caution aside, our analysis does indicate that the bias would be relatively small and, if existent, would likely have only a minimal effect. If there existed a strong site fidelity within the Hawaiian Islands, and therefore a large bias, it is likely that it would have been revealed in this analysis.

Second, there is evidence that subgroups of individuals may move in aggregate. This could introduce a bias similar to temporary emigration if a group of associated individuals moved into an area during 1 season, were absent during the next, and then returned the subsequent year. When sampling off a single island, it is irrelevant whether groups emigrate to a different region of the islands or away from the Hawaiian Islands altogether (as docmented by Darling \& Jurasz 1983, Darling \& Cerchio 1993); the result is still varying capture probability across years that is not random or independent among individuals. This violation of equal capture probability could result in population estimates from 1 island being biased positively (Begon 1979, Seber 1982, Baker \& Herman 1987), as described by hypothesis (3).

There is a prevailing implicit assumption in humpback whale literature that whales from highly structured feeding sub-populations migrate each year to aggregate breeding areas and mix into a random, unstructured breeding assemblage. It is reasonable to entertain the alternative assumption that whales from different feeding regions may maintain some cohesiveness, moving through the breeding area in a coordinated manner, or at least following similar migratory routes. Evidence from this study and that reported by Darling (1983) indicate that groups of individuals may synchronize movements. Darling \& Morowitz (1986) reported evidence that the composition of individuals off Maui varied from year to year. Cerchio $(1995,1998)$ reported evidence of temporary emigration during a 5 yr period off Kauai, and concluded that composition of individuals off Kauai varied from year to year in a non-random manner. Each of these observations, although not providing definitive evidence, support a general conclusion of non-random movement patterns among individuals. An appropriate analogy may be herds of African ungulates, such as the common wildebeest Connochaetes taurinus, in which large numbers of individuals synchronize movements and sometimes move extensive distances in aggregate (Sinclair et al. 
1985). Separate individuals at opposite ends of a herd may never directly associate with each other, or be sighted at the same location within days of each other; however, movement among the entire group is coordinated. Furthermore, sympatric sub-populations of $C$. taurinus can exhibit very different movement patterns, some being sedentary and others highly mobile (Eloff 1966). It is a reasonable suggestion that humpback whales may exhibit similar tendencies, with multiple subgroups migrating to and from, as well as moving throughout, the Hawaiian Islands together. Different subgroups may also exhibit different patterns of movement while on wintering grounds. This is further supported by the common observation of local whale abundance fluctuating throughout the season in 'pulses' (authors' pers. obs.). If such patterns exist, then there is potential for non-random variation in capture probability among individuals and through time, or temporary emigration of subgroups. We believe that the existing evidence warrants researchers to seriously consider this possibility, and design more extensive sampling to test the hypothesis.

This description of humpback whale movement between Kauai and Hawaii raises some compelling questions about inter-island movement in general. However, no study of inter-island movement is complete without data from west Maui and Penguin Bank, the areas of the Hawailan Islands where population densities are greatest (Mobley \& Bauer 1991, Mobley et al. 1994). For example, it remains possible that exchange between Hawail and the Maui/Penguin Bank regions are greater than that for either of these areas with Kauai. Alternatively, there may be greater exchange between Maui/Penguin Bank and both Hawail and Kauai than between the latter 2 islands. Each of these possibilities would have different implications for abundance estimation. From the analyses presented here, it seems clear that only a directed mark-recapture sampling regime covering all the Hawaiian lslands, and designed to collect a large sample size from all areas of concentration, would elucidate movement patterns of individual whales through the islands. With such a study, the actual biases associated with individual movement could be quantified and then be taken into consideration in the development of unbiased estimation models.

Acknowledgements. Many individuals were involved in the collection of data for this study. In Kauai, photographers and contributors were Dan Shapiro, Thea Jennsen. Johanna Slob, Marci Greenberg, Ruth Lewis, Jackie Murphy and Chuck Moon. Bernd Würsig was instrumental in getting the project started. In Hawaii, contributors in the field were Adam Frankel, Rick Coleman, Tom Freeman, David Helweg, Mike Hoffhines, Barry Patterson and Suzanne Yin. Virginia Murphy and Kimberly Snyder assisted with fluke matching. We thank Hal Whitehead for his assistance in the development of the random modeling. John Megahan created the study site figure. The manuscript was improved by the comments of John Calambokidis, Jay Barlow and several anonymous reviewers. Funding for the Kauai portion of this study was provided by Whale Aid, Earthtrust, the American Cetacean Society - Monterey Bay, Los Angeles and National chapters, the Animal Behavior Society, Sigma $X i$, the American Museum of Natural History, the Myers Foundation for Marine Research, and the Packard Foundation. Moss Landing Marine Laboratories and its staff provided much needed institutional support. The Hawail portion was funded by the Center For Field Research (Earthwatch). The NOAA Sanctuaries and Reserves Division provided support for analysis and writing. All data collection was conducted under National Marine Fisheries Scientific Research Permit no. 663 off Kauai and no. 576 off Hawaii.

\section{LITERATURE CITED}

Baker CS, Herman LM (1981) Migration and local movement of humpback whales (Megaptera novaeangliae) through Hawaiian waters. Can J Zool 59:460-469

Baker CS, Herman LM (1987) Alternative population estimates of humpback whales (Megaptera novaeangliae) in Hawaiian waters. Can J Zool 65:2818-2821

Baker CS, Herman LM, Perry A, Lawton WS, Straley JM, Wolman AA, Kaufman GD, Winn HE, Hall JD, Reinke JM, Östman J (1986) Migratory movement and population structure of humpback whales (Megaptera novaeangliae) in the central and eastern North Pacific. Mar Ecol Prog Ser 31:105-119

Bauer GB (1986) Impacts of vessel traffic on humpback whales in the Hawaiian Islands. Doctoral dissertation, University of Hawai, Honolulu

Begon M (1979) Investigating animal abundance: capturerecapture for biologists. University Park Press, Baltimore

Calambokidis J, Cubbage JC, Steiger GH, Balcomb KC, Bloedel P (1990) Population estimates of humpback whales in the Gulf of the Farallones, California. Rep Int Whal Comm Spec Issue No. 12:325-333

Cerchio S (1995) Estimates of humpback whale abundance off Kauai, 1989 to 1993, indicate non-random mixing among the Hawaiian Islands. In: Abstracts, 11 th Biennial Conf Biol Mar Mammals, Orlando, Florida, December $14-18,1995$

Cerchio S (1998) Estimates of humpback whale abundance off Kauai, 1989-1993: evaluating biases associated with sampling the Hawaiian Islands breeding assemblage. Mar Ecol Prog Ser 175:23-34

Cerchio S, Gabriele C, Frankel A (1991) Inter-island movements of humpback whales in the Hawaiian Islands: three seasons off Kauai and Hawaii. In: Abstracts, 9th Biennial Conf Biol Mar Mammals. Chicago, Illinois, December 5-9, 1991

Clapham PJ, Palsbøll PJ, Mattila DK, Vásquez O (1992) Composition and dynamics of humpback whale competitive groups in the West Indies. Behaviour 122:182-194

Darling JD (1983) Migrations, abundance and behavior of 'Hawaiian' humpback whales (Megaptera novaeangliae). Doctoral dissertation, University of California, Santa Cruz

Darling JD. Cerchio S (1993) Movement of a humpback whale (Megaptera novaeangliae) between Japan and Hawaii. Mar Mamm Sci 9:84-89

Darling JD, Jurasz CM (1983) Migratory destinations of North Pacific humpback whales (Megaptera novaeangliae). In: Payne $R$ (ed) Communication and behavior of whales. 
AAAS Selected Symposia Senes. Westriew Press, Boulder, p 359-368

Darling JD, McSweeney DJ (1985) Observations of the migrations of North Pacific humpback whales (Megaptera novaeangliae). Can J Zool 63:308-314

Darling JD, Mori K (1993) Recent observations of humpback whales in Japanese waters off Ogasawara and Okinawa. Can J Zool 71:325--333

Darling JD, Morowitz H (1986) Census of 'Hawaiian' humpback whales (Megaptera novaeangliae) by individual identification. Can J Zool 64:105-111

Darling JD, Gibson KM, Silber GK (1983) Observations on the abundance and behavior of humpback whales (Megaptera novaeangliae) off West Maui, Hawaii, (1977-79). In: Payne R (ed) Communication and behavior of whales AAAS Selected Symposia Series. Westview Press, Boulder, p 201-222

Eloff FC (1966) Range extension of the blue wildebeest. Koedoe $9: 34-36$

Gabriele CM (1992) The behavior and residence characteristics of reproductive classes of humpback whales (Megaptera novaeangliae) in the Hawailan Islands. MSc thesis, University of Hawaii, Honolulu

Glockner DA (1983) Determining the sex of humpback whales (Megaptera novaeangliae) in their natural environment. In: Payne R (ed) Communication and behavior of whales. AAAS Selected Symposia Series. Westview Press, Boulder, p 447-464

Glockner-Ferrari DA, Ferrari MJ (1985) Reproduction in humpback whales (Megaptera novaeangliae), in Hawaiian waters. Rep Int Whal Comm Spec Issue No. 6:237-242

Hammond PS (1986) Estimating the size of naturally marked whale populations using capture-recapture techniques. Rep Int Whal Comm Spec Issue No 8:253-282

Editorial responsibility: Otto Kinne (Editor),

Oldendorf/Luhe, Germany
Hammond PS (1990) Heterogeneity in the Gulf of Maine? Estimating humphack whale population size when capture probabilities are not equal. Rep Int Whal Comm Spec Issue No. 12:325-333

Katona S, Baxter B, Brazier O, Kraus S, Perkins J, Whitehead $H(1979)$ Identification of humpback whales by fluke photography. In: Winn HE, Olla BL (eds) Behavior of marine animals, Vol 3. Plenum Press, New York, p 33-44

Manly BFJ (1997) Randomization, bootstrap and Monte Carlo methods in biology, 2nd edn. Chapman and Hall, London

Mobley JR Jr, Bauer GB (1991) Changes in distribution of humpback whales on the Hawaiian wintering grounds: 1990 aerial survey results. In: Abstracts, 9th Biennial Conf Biol Mar Mammals, Chicago, December 5-9, 1991

Mobley JR, Herman LM. (1985) Transience of social affiliations among humpback whales (Megaptera novaeangliae) on the Hawaiian wintering grounds. Can J Zool 63: $763-772$

Mobley JR, Forestell PH, Grotefendt R (1994) Results of 1993 aerial surveys in Hawailan waters. In: 1993 ATOC Marine Mammal Research Program: Annual Report to Advance Research Projects Agency

Seber GAF (1982) The estimation of animal abundance and related parameters. Macmillan Publishing Co, New York

Sinclair ARE, Dublin H, Borner M (1985) Population regulation of Serengeti wildebeest; ${ }_{i}$ a test of the food hypothesis. Oecologia 65:266-288

Urbán J, Jaramillo A, Salinas $M$, Jacobsen J, Balcomb K, Ladron de Guevara P, Aguayo A (1994) Population size of the humpback whale (Megaptera novaeangliae) in the Mexican Pacific. Working Paper SC/46/NP4 to the Int Whal Comm

Zar JH (1984) Biostatistical analysis, 2nd edn. Prentice-Hall, Englewood Cliffs, NJ

Submitted: January 16, 1998; Accepted: August 10, 1998

Proofs received from author(s): December 10, 1998 